\title{
LA-5517-MS
}

INFORMAL REPORT

\section{Conceptual Design of a \\ Coring Subterrene Geoprospector}


This report was prepared as an account of work sponsored by the United States Government. Neither the United States nor the United States Atomic Energy Commission, nor any of their employees, nor any of their contractors, subcontractors, or their employees, makes any warranty, express or implied, or assumes any legal liability or responsibility for the accuracy, compieteness or usefulness of any information, apparatus, product or process disclosed, or represents that its use would not infringe privately owned rights.

In the interest of prompt distribution, this LAMS report was not edited by the Technical Information staff.

Printed in the United States of America. Available from National Technical Information Service

U. S. Department of Commerce 5285 Port Royal Road

Springfield, Virginia 22151

Price: Printed Copy $\$ 4.00$; Microfiche $\$ 1.45$ 


\title{
Conceptual Design of a
}

\section{Coring Subterrene Geoprospector}

by

\author{
J. W. Neudecker
}

Work supported in part by a grant from the National Science Foundation, Research Applied to National Needs (RANN).

This report was prepared os an account of work
sponsored by the United States Government. Neither
the United States nor the United States Atomic Enesgy
Commission, nor any of their employees, nor any of
their contractors, subcontractors, or their employees,
makes any warranty, express or implied, or assumes any
legal liability or responsibility for the accuracy, com-
pleteness or usefulness of any information, apparatus,
product or process disclosed, or represents that its use
would not infringe privately owned rights.


CONCEPTUA: DESIGN OF A CORING SUBTERRENE GEOPROSPECTOR

by

J. W. Ntudecker

ABSTRACT

A rock-melting Subterrene system is described that can obtain a continuous core along the projected route of a tumnel. System specifications, individual component functions, preliminary design concepts, and design alternatives are included; and subcomponents that can be assembled from commercially available hardware are indicated. The device requires $150 \mathrm{~kW}$ of electric power to melt an accurate $300-m \mathrm{~m}\left(1-\mathrm{ft}^{+}\right)$-diam glasslined hole and removes a 200-mm (8-in.)-diam glass-cased core at an advance rate of $0.4 \mathrm{~mm} / \mathrm{s}(5 \mathrm{ft} / \mathrm{h})$. The accurate hole diameter and stable hole lining allow the use of a packer-thruster located at the heated hole-melting and hole-forming penetrator assembly. An orientation sensor and a guidance unit can also be located in this assembly. A hollow, flexible stem trailing behind the assembly contains the electric-power, coolant, and instrumentation lines, and provides a passage for debris removal. Core sections are removed through the flezible stem intermittently with wire-line core-retrieval hardware. This Subterrene system, named Geoprospector, is essentially a self-propelled and surface-guided minitunneler: It is a logical major development step in the Subterrene program, directed toward a lirger-diameter tunneling machine. Other practical Geoprospector applicaticiss are the forming of noles under obstacles such as rivers, niginways, buildings, or other structures to accommodate utility lines or cables; the implantation of urban utilities; and the installation of underground pipelines or power-transmission lires without ditching.

\section{INTRODUCTION}

\section{Program Background}

New devices for excavating, based on the concept of rock-melting (termed Subterrene) are being developed at LASL. ${ }^{1}$ Ultimately, the program visualizes that large tunnels ${ }^{2}$ and deep probes (e.g., to tap geothermal energy sources) will be melted with a nuclear-powered, self-propelled device called a Nuclear Subterrene. This device is expected to tunnel through a variety of ground formations, ranging from hard, dense rock to loosely consolidated materials. Preliminary technical and economic studies are being conducted with devices of relatively small diameter that are conveniently operated with electric power. A variety of these electrically heated prototype penetrators 3,4 have been designed and tested successfully. ${ }^{5}$ Laboratory and field tests have demonstrated the feasibility of the basic concepts and have indicated a wide range of potential applications. ${ }^{6}$ Experiments designed to investigate the formation and disposal of liquid rock melt have verified that new solutions are offered in the three major problem areas of the excavation process

- making the borehole or tunnel,

- supporting the wall, and

- handling the debris.

The design and development of prototypes [including a 75-mm (3-in.)-diam horizontal hole melter $],{ }^{7}$ data from experiments and tests, and supporting theoretical analyses have shown that preliminary 
design concepts can be identified for a variety of Subterrene systems for numerous different applications.

The Subterrene system iscussed herein is a relatively small-diameter (300-mu) electrically powered tunneler that cculd be programmed and remotely guided to form a hole alcng a proposed underground route and to extract core samples continuously, thus providing a complete geological record prior to costly major drilling operations. In addition, the Geoprospector, serving as a small-scalc prototype, will indicate solutions to problems that will arise in the development of larger, nuclearpowered Subterrene tunnelers.

\section{Study Objectives}

Critical design details of the Geoprospector system will be established from other, smaller, Subterrene devices. Successfully field-tested technological innovations will be incorporated, with suitable modifications, into the Geoprospector design. Theoretical analyses of preliminary design concepts will be used for optimization of various components. In addition, layouts and specifications will permit an early selection of prospective materials. An early conceptual design will thus evolve that will form the basis for component definition and for the formulation of a protctype test schedule.

Specifically, this conceptual design study will:

- Establish basic system dimensions and functions;

- Outline system specifications;

- Define the various subsystem components;

- Indicate general component concepts, problem areas requiring development effort, and possible solutions;

- Integrate the various components into a tentative Geoprospector system;

- Form a basis for preliminary costing; and

- Delineate laboratory and field tests.

This information will permit us to define a final design and to develop a program for a useful device.

\section{DESIGN CONCEPTS}

\section{System Concepts}

The general design features of the Geoprospector system are illustrated in the isometric sketch shown in Fig. 1. The system as presently conceived consists of six major components and subsystems:
- Melting coring penetrator.

- llole-forming and glass-chilling afterbody.

- Melt-debris-handling unit.

- Packer-thruster drive and guidance section.

- Position-sensor package.

- Flexible stem and core-retrieval hardware. Surface-located auxiliary units are:

- Electric puwer supply.

- Coolant supply.

- Stem-handling equipment.

- Core-handling unit.

- Retraction device.

- Operation monitors and controls.

- Position monitors and automatic guidancecontrol center.

The system schematic, Fig. 2, indicates the major functions and interactions of these components and auxiliary units.

Self-propelling of this unique horizontal coring device is made possible by a glass lining of accurate diameter formed on the hole wall. This precisely dimensioned and stable wall allsws the use of a thrust unit that packs or grips onto the glass lining and thrusts against the packer. The point of locomotion can therefore be located only a short distance aft of the hole-melting penetrator and thus avoids the need for thrusting from the surface through a rigid stem. Because electric power lines lead to the hole-forming assembly and because instrumentation cables are run through the flexible stem, it is possible to include position sensors at the penetrator and to provide control signals for guidance without major technical difficultie..

\section{PERFORMANCE SPECIFICATIONS}

Preliminary performance specificatons for the Geoprospector are summarized in TabIe I. Factors relating to the values shown in the table are summarized as follows:

Dimensions

The outer diameter of the device is selected to be $300 \mathrm{~mm}$ ( $12 \mathrm{in.}$. Based upon current design limits, this diameter is the smallest that can accommodate the required annular volune to contain the packerthruster systems and still permit the extraction of a sizable core. On the other hand, this seems to be the largest penetrator body that can be currently consiructed from a single forged billet of 


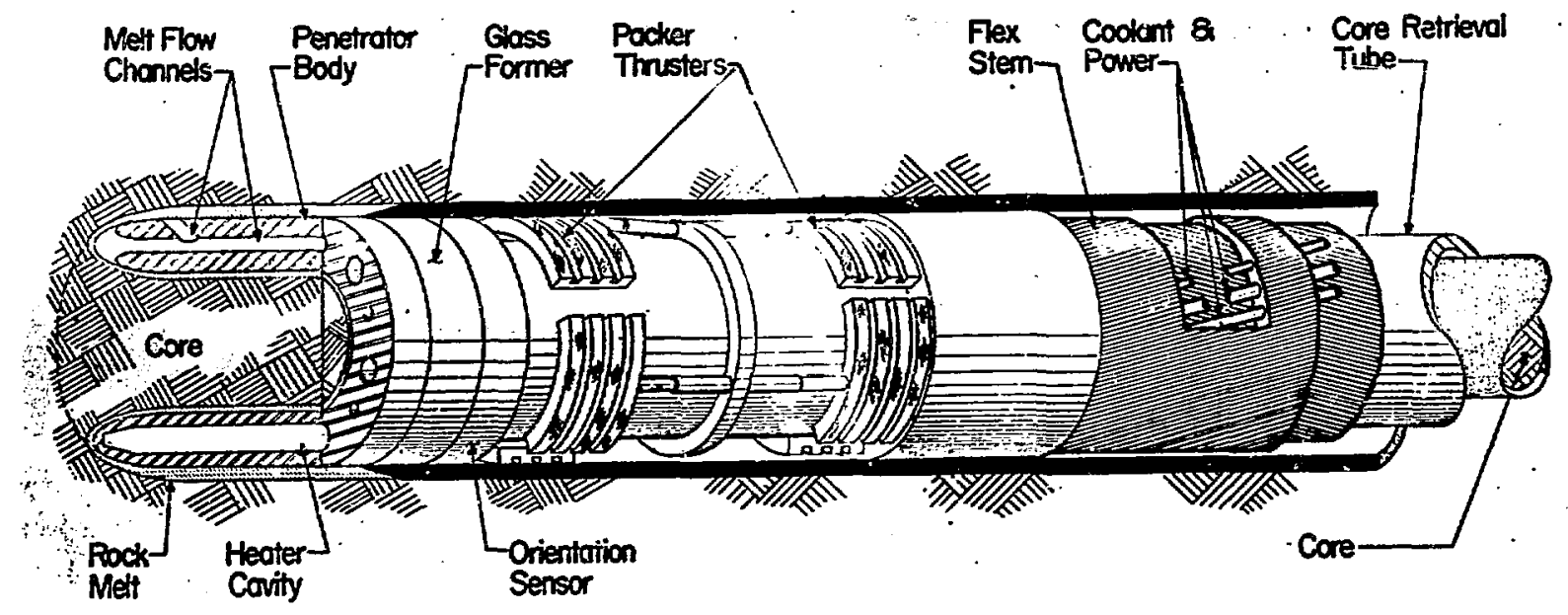

Fig. 1. Geoprospector.

molybdenum by using present refractory-metal fabrication capabilities; as an alternative, the Guoprospector melting penetrator could be assembled from individual modules. The diameter of the unmelted, glass-cased core has been selected at $200 \mathrm{~mm}$ ( 8 in.), so that the thickness of the annular space is $50 \mathrm{~mm}$ ( 2 in.) -- the minimurn needed to accommodate the systems. A thicker annular ring (hence smaller core) could be considered but would réuuire more melting power.

\section{Advance Rate}

To ensure long service life, maximum temperatures of 1870 and $2070 \mathrm{~K}$ have been selected for the molybdenum and tungsten penetrator bodies, respectively.

An advance rate of $0.4 \mathrm{~mm} / \mathrm{s}(5 \mathrm{ft} / \mathrm{h})$, considered the minimum useful rate, is an extrapolation of current developments for a melter of this size. Whether or not this rate is satisfactory will de-. pend largely on the ability to maintain the rate

SYSTEMS FUNCTION KEY

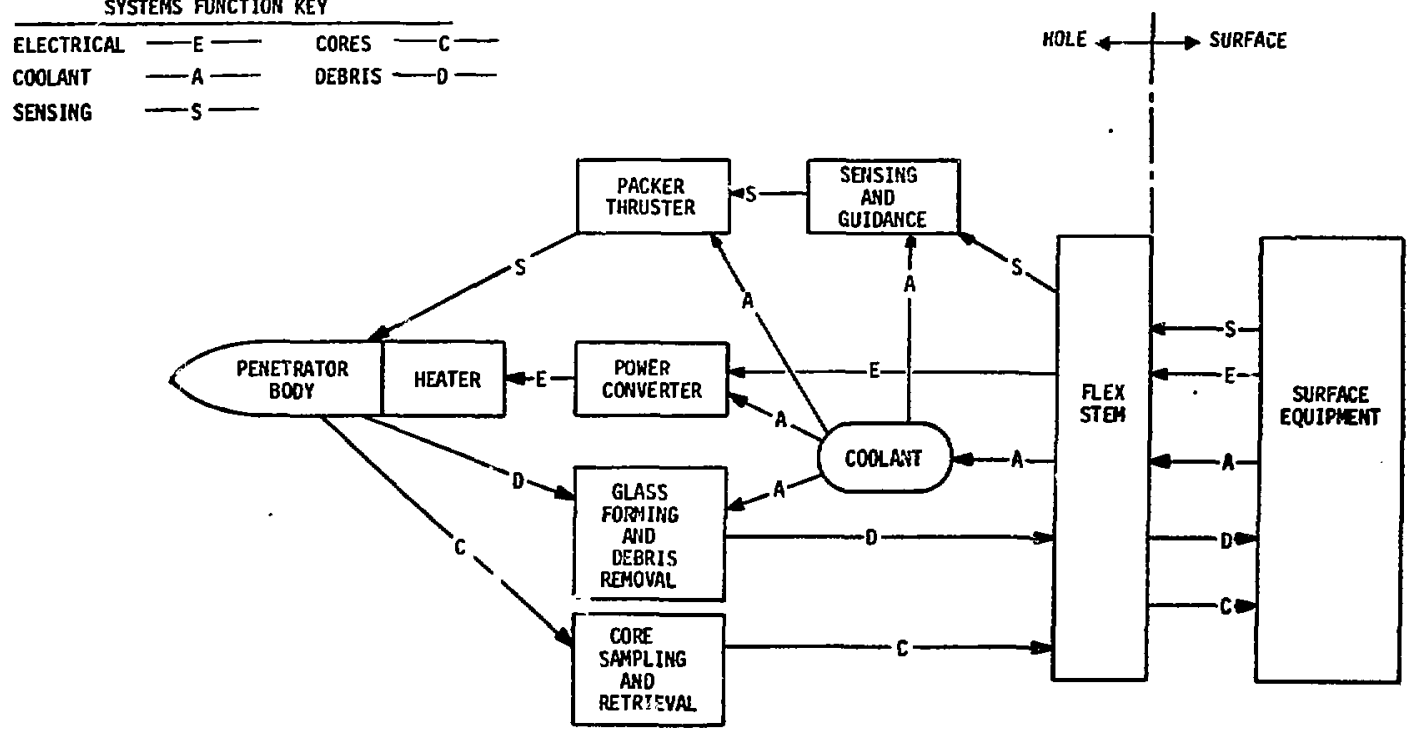

Fig. 2. Geoprospector system schematic diagram. 
continuously for long periods of time, i.e., nearly $100 \%$ utilization of the Geoprospector in the fisld. Thermal Power

The heater power level of $100 \mathrm{~kW}$ is based upon penetracor efficiency, hole size, and advance rate considered. This power is the upper limit of present state-of-the-art electric heater designs.

Electric Heater Characteristics

The design power of $100 \mathrm{~kW}$ can be attained by $40 \mathrm{~V}$ at $2500 \mathrm{~A}$. For penetrators as large as $300 \mathrm{~mm}$ in diameter the trend is toward higher currents which require conductors of large cross-sectional area. A current of $2500 \mathrm{~A}$ is probably the upper practical limit that can be transmitted over distances up to $5 \mathrm{~km}$. It would be desirable to develop heater arrangements with increased effective resistance so that the same power could be obtained with higher voltages and smaller currents, e.g. $100 \mathrm{~V}$ at $1000 \mathrm{~A}$. As an alternative, one could consider higher transmission voltages with a converter at the hole-forming assembly.

Advancing Thrust Load

Tentatively, a thrust load of $50 \mathrm{kN}$ was se- lected, which wijl be created by the packer-thruster system. Preliminary analyses indicate this tinrust will be sufficient to maintain the advance rate and to permit steering of the penetrator body through the melted rock.

Position Sensing Accuracy

The accuracy of penetration is specified to be within an angular error of $10^{-3} \mathrm{rad}$. This value is adequate to facilitate guidance, yet is within the state of the art of sensor units (see appendix). The location of the device must be determinable to within $\pm 1.0 \mathrm{~m} / \mathrm{km}$ of total melting distance.

\section{I?. SYSTEM DEFINITION}

The Geoprospector (Fig, 1) consists of several components, which interact as shown in the schematic sketch, Fig. 2. The interactions and functions of each of tinese components are described below.

A. Penetrator Body and Melting Surface

The penetrator body and the melting surface are shown in Fig. 3. The melting face wili have as many as twelve small openings or flow channels through which the rock melt will flow to chill-jet nozzles,

\begin{tabular}{|c|c|c|}
\hline Quality & & Value \\
\hline Outer dianeter, mm (in.) & 300 & $(12)$ \\
\hline Diameter of extracted cores, $\operatorname{mom}$ (in.) & 200 & $(8)$ \\
\hline Length range, $\mathrm{km}$ (mi) & 5 & $(3.1)$ \\
\hline Melter temperature, $K\left({ }^{\circ} F\right)$ & 1870 & $(2910)$ \\
\hline Advance rate, $\mathrm{mm} \cdot \mathrm{s}^{-1}\left(\mathrm{ft}-\mathrm{h}^{-1}\right)$ & 0.4 & (5) \\
\hline Thermal power required, $k w$ & 100 & \\
\hline \multicolumn{3}{|l|}{ Heater electrical characteristics } \\
\hline Potential, $V$ & 40 & \\
\hline Current, A & 2500 & \\
\hline Advancing thrust load, $\mathrm{kN}\left(\mathrm{lb}_{\mathrm{f}}\right)$ & 50 & $(11,000)$ \\
\hline \multicolumn{3}{|c|}{$\begin{array}{l}\text { Accuracy of position sensing: The sensor system shall } \\
\text { be capable of detecting an angular error of } 10^{-3} \\
\text { rad and of generating a correcting directional signal. }\end{array}$} \\
\hline \multicolumn{3}{|c|}{$\begin{array}{l}\text { Accuracy of location: A combination of penetration distance } \\
\text { and integration of directional deviations will permit } \\
\text { calculation of penetrator position to } \pm 1.0 \mathrm{~m} \text { per kilo- } \\
\text { metre of total melting distance. }\end{array}$} \\
\hline
\end{tabular}




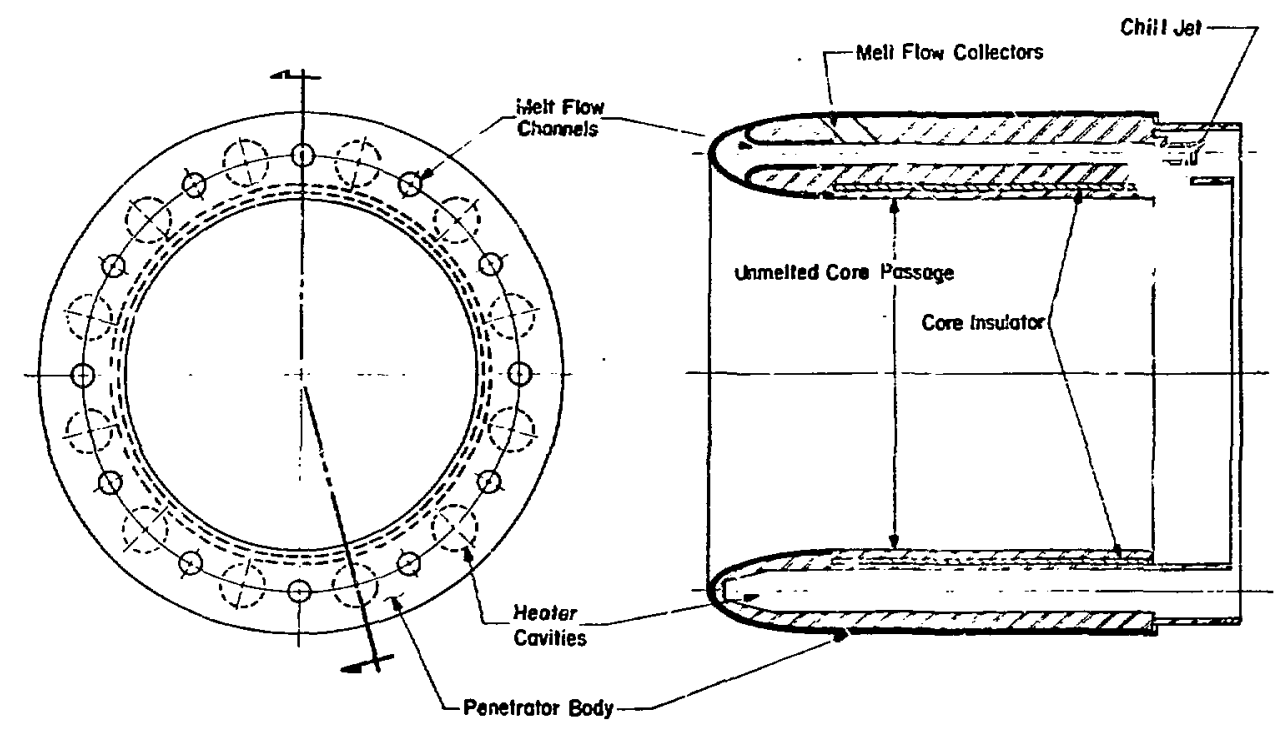

Fig. 3, Penetrator body。

which will freeze the melt irto small paricles of rock glass; this debris is subsequencly removed via the stem by the cooling fluid. The penetrator body will operate at a surface temperature of $1870 \mathrm{~K}$ and will be fabricated from a forged molybdenum-tungsten alloy either as a rolled, continuous ring or will be assembled from individual modular units. The penetrator body will be designed to withstand the $50-\mathrm{kN}$ thrust load applied by the packer-thruster system to the melting surface. A heater terminal is located between each melt-flow channel and chill-jet nozzle. Each heater cavity will accommodate the hot end of one heater unit. Flutes and auxiliary melt-flow channels will enhance the ef:ectiveness of the rockmelting process and will divert the melted rock to the melt-flow channels leading to the chill-jet nozzles. Except for the factors governed by the relatively large size of the assembled 300-nm-diam penetrator, all the technology necessary to build and operate the penetrator body is well in hand and is being proved in the current rock-melting research and development program. For example, the coaxial chill-jet principle of removing scoria while melting holes in hard, dense rocks (e.g., granite and basalt) as well as in low density materials has been tested. B. Heaters

The electrical heaters and associated heattransfer components convert electric energy into thermal energy to heat the penetrator body and the melting face. As shown in Fig. 3 there are twelve heaters, each capable of converiing $\sim 12 \mathrm{~kW}$ of thermal energy but operating at only $8.3 \mathrm{~kW}$, for an cverall total power level of $100 \mathrm{~kW}$. Two alternative heater design options are available as shown in Fig. 4. First, the heater may be located in the penetrator body adjacent to the melting surface. In this case the heater would consist of radiant heater elements made up of a stack of pyrolytic-graphite disks. Similar heaters have been tested extensively in a variety of prototype rock-meliting devices. ${ }^{8}$ Nominal operating characteristics of each of these radiant
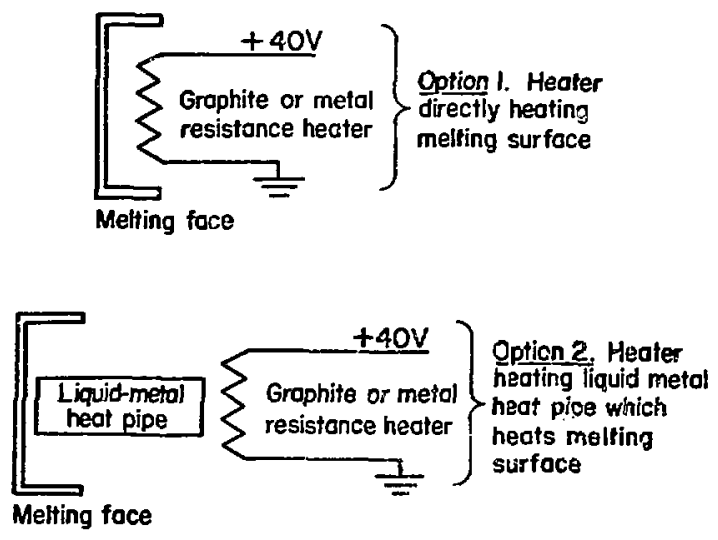

Fig. 4. Heater option. 
heaters wolild be $\sim 210 \mathrm{~A}$ at $\sim 40 \mathrm{~V}$ for a power level of $\sim 8.3 \mathrm{kl}$ each.

Second, the heaters could be located at a distance and the thermal energy uould be transmitied to the melting surface through heat pipes using liquid metal as the working fluid. ${ }^{9}$ Such high-temperature heat pipes were invented and develeped at Lisl. and are considered suitable for this application as indicated by extensive testing.

The relative advantages of the two heater systems will be examined critjcally and can be developed in parallel during the preliminary design offort.

\section{Cooling}

The coolant system of the Geoprospector, shown schematically in Fig. 5, serves tve purposes:

(1) it provides the coolant for moderating the temperature aft of the high-tenperature heater and penetrator body, and (2) it transports the rock-melt debris (scoria or "cuttings") out of the hole. The coolant may be either a gas (compressed air or nitrogen) or a liquid (water). Soth gas and water have been utilized successfully in subterrene sistems. The choice between the two depends upon the heat load to be carried by the coolant systen, upon the relative effectiveness of the two methods for removing the deoris, upon overall system considerations, and upon operational availaoility of the two fluids.

\section{Rock Glass Forming and Debris Removal}

The two major functions of the glass-forming and debris-removal system are:

- Build up a dense structural glass lining on the wall of the hole, and

- Duct the melted rock from the annular melting face through the chill jets where the melt will mix with the coolant, be frozen into glass particlec, fluidized, and carried out through the $f_{1} \mathrm{ex}$ stem with the returning coolant flow.

Both functions can he provided for by appropriate structural arrargements, supplemented, if necessary, by selective heating from auxiliary heaters. The concept of a glass-forming and debris-removal system is shown in Fig. 6.

\section{ᄃ. Power Susply}

The simple power supply system, outlined in Fig. 7 , consists of electrical conductors which transmit the electrical energy from the slirface through the ilexible stem to a voltage converter that changes the the suppiy voltage to the optimum value for operating the clectric heaters. " The power supply system is completed by the electric-current return path through the sten:.

\section{F. Oriertation Sensing and Guidance}

The ceoprospector will be equipped with orientation-sensing. and guidance systems that will direct the licoprospector along a preselected route through the earth. 'telting progress and positional attitude vill be mionitored continuously. Deviations will be sensed and corrccting signals will be applied to the steering components of the packer-thruster system.

Figure 8 show's schematically the operation of the orientation-sensing and guidance system;

Table II briefly out lines the instrumentation requirements and specifies the resolution and range of the sensors. All sensing elements will be adapta$t$ ions of commercially available units, and their integration into a sensing and guidance system is considered state of the art.

Alternately, it may be possible to connect heaters in series and lower the current required.

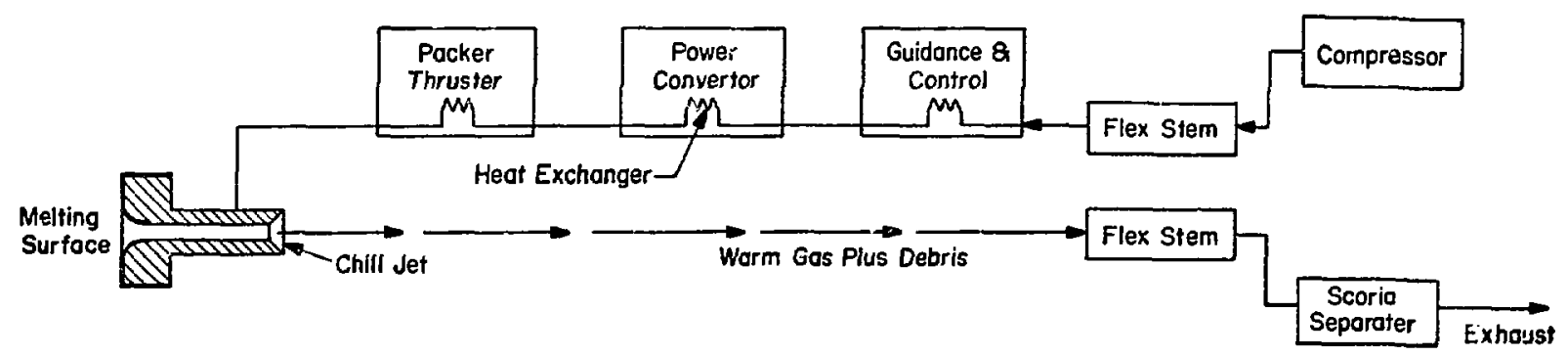

Fig. 5. Cooling System. 


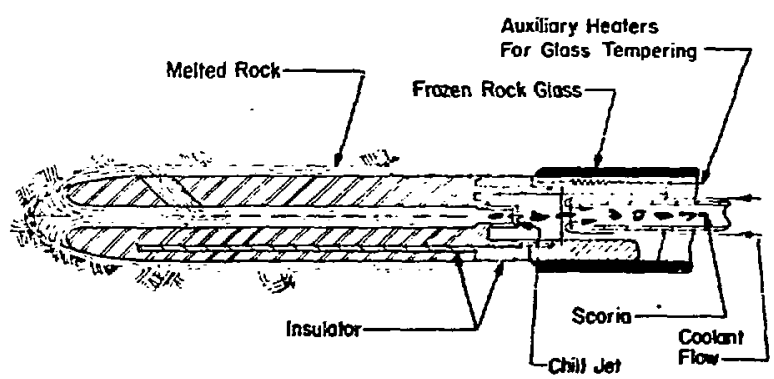

$\mathbf{z}$

Fig. 6. Glass forming and debris removal.

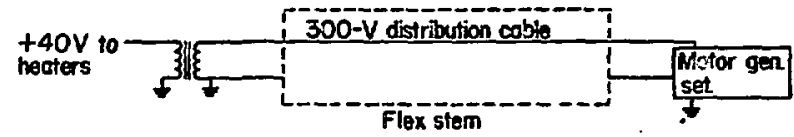

Fig. 7. Power supply.

\section{G. Packer-Thruster}

The packer-ihruster system applies to the melting. penetrator both a programmed thrust load and the differential thrust loads that are used to steer the hole-forming assembly aling the desired path of the hole. The major design problems of the packerthruster syster: arise from the very narrow annular space available for accommodating and operating the system. This annular space will have a width of $\sim 35 \mathrm{~mm}$.

Table I lists an advancing thrust load of $50 \mathrm{kN}$. If we assume a friction coefficient on the sides of the glass-lined hole of 0.10 , a radial packer load of $500 \mathrm{kN}$ would be required.

The packer-thruster design concept shown in Fig. 9 takes advantage of the fact that the glass lining formed hy the Ceoprospector is very uniform in diameter and is relatively smooth. The packer units are thin-walled steel rings that are pressurized internally by a thin annular hydraulic chamber. The packer has a nominal diameter that is slightly smaller than that of the glass liner. A low-pressure hydraulic fluid expands the thin steel cylinder until the cylinder hears against the glass-lined wall;

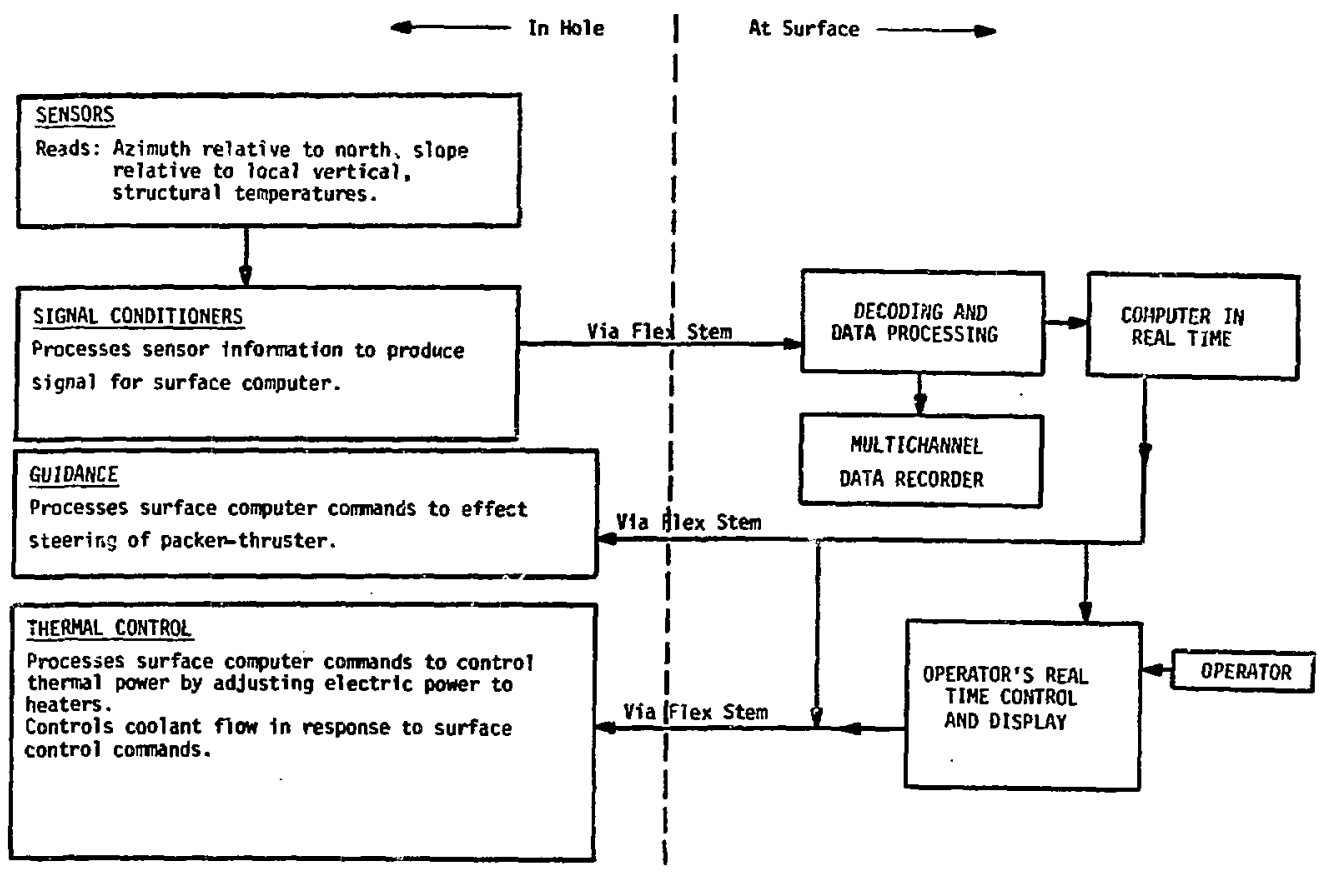

Fig. 8. Orientation sensing and guidance. 


\begin{tabular}{|c|c|c|c|}
\hline System & Sensing Element & Resolution & Range \\
\hline Material temperature of melter & Thermocouple & $\pm 5 \mathrm{~K}$ & $500-1900 \mathrm{~K}$ \\
\hline Advancing force & Load cells & $\pm 500 \mathrm{~N}$ & $0-130 \mathrm{kN}$ \\
\hline \multirow[t]{2}{*}{ Electric pawer } & Voltmeter & $\pm 0.05 \mathrm{~V}$ & $0.50 \mathrm{~V}$ \\
\hline & Ammeter & $\pm 10 \mathrm{~V}$ & $0-3000 \mathrm{~A}$ \\
\hline \multirow[t]{4}{*}{ Position } & Accelerometers & $\pm 5 \times 10^{-6} \mathrm{~g}$ & $0-0.1 \mathrm{~g}$ \\
\hline & Magnetometers & $\pm 1 \times 10^{-3} \mathrm{rad}$ & $2 \pi \mathrm{rad}$ \\
\hline & Linear distance scale & $\pm 1 \mathrm{~m}$ & $10 \mathrm{~km}$ \\
\hline & Inclinometer & $\pm 1 \times 10^{-3} \mathrm{rad}$ & $\pi \mathrm{rad}$ \\
\hline
\end{tabular}

further :ydraulic pressure then applies a radial force to the glass liner that immobilizes the packer. Axial forward thrust is applied to the hole-forming assembly by small hydraulic actuators that react against the locked-in-position packer. Two separate packer assemblies provide alternating packing and resetting for continuous thrusting and forward motion of the penetrator. Additional packerthrusters can be provided to enhance reliability and to function as eccentric thrusters that yield transverse forces for directional guidance.

11. Stem

The tubular, flexible stem will enclose the systems that lead from the surface to the penetrator, namely the guidance-system control link, the coolant passages, the electric power line, the debris-removal passage, and the central coreretrieval passage. Because the Geoprospector performance goal is a range of $5 \mathrm{~km}$, the stem must be designed for this distance. Tentatively, the stem

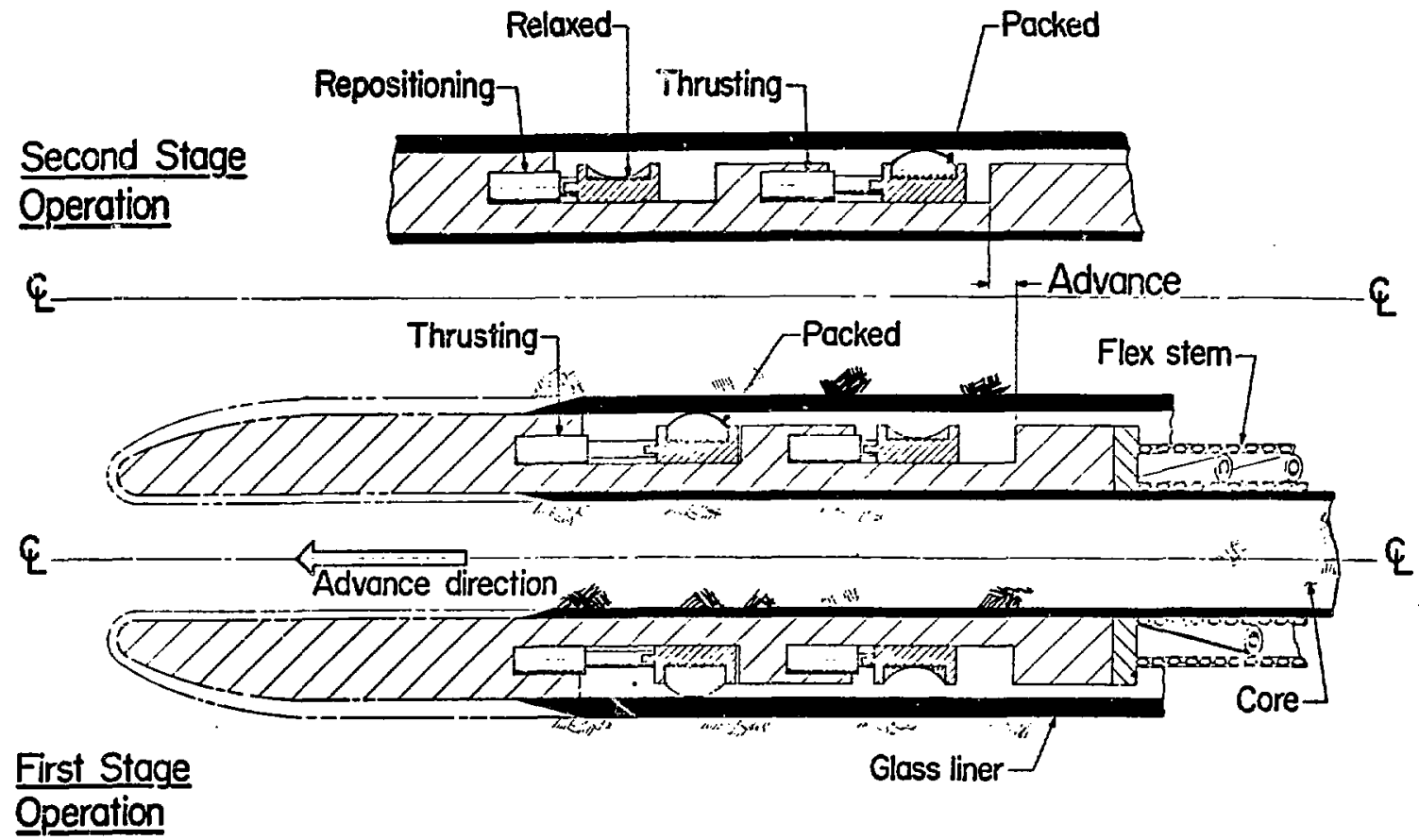

Fig. 9. Packer-thruster system. 
will consist of thin-walled, flexible, woven steel conduit for most of its length. A short,

$\sim 10-m-$ long, rigid stem will be attached to the aft end of the packer-thruster and will be pulled along with the melting unit. Because the mass and hence the frictional drag load of the stem in the glasslined hole will become quite large at lengths over one kilometre, roller bearings or glidurs must be designed as integral parts of the stem tc refuce this drag force and to facilitate stem movement. I. Core Sampling and Retrieval

The core sampling-and-retrieval system will bc an adaptation of standard core-retrieval hardware. The cores will have an outer diameter of $200 \mathrm{~mm}$. Because the melting face forms an annular hole in the rock or soil formation, the cores will be generated as a continuous by-product of the holemelting process. The length of the core removed at each retrieval trip can be adjusted, within limits, depending on the curvature of the hole path. The flexible stem will be capable of negotiating a relatively sharp bend in the path, but a long core would not be able to pass such a bend. The core will therefore be retrieved continuously in lengths consistent with the advance rate of the holeforming assembly, the curvature of the path, and the round-trip time. A numerical example of this relationship follows.

Assume an advance rate of $0.5 \mathrm{~mm} / \mathrm{s}(\sim 5 \mathrm{ft} / \mathrm{h})$ and a trip time of $2 \mathrm{~h}$ for the core-retrieval system. Then, for compatible core-retrieval operations, the system must handle an $\sim 3-\mathrm{m}(\sim 10-\mathrm{ft})-$ long core each trip. In addition, the sharpest bend in the flexible stem must have sufficient inside clearance to permit passage of the 3-m-long core.

\section{J. Surface Equipment}

Surface equipment includes the following items.

1. Electric Power Supply. Electric power of $150 \mathrm{~kW}$ is supplied from the ground level to the stem. This power may be taken from a commercial power-distribution system and is converted in two stages from commercial distribution voltages to penetrator heater voltage. For example, the commercial distribution line may supply $11000 \mathrm{~V}$ at $\sim 15 \mathrm{~A}$. This voltage and current could be converted to $480 \mathrm{~V}$ at $230 \mathrm{~A}$ at the ground level before bein $\tilde{E}$ transmitted by the conductors in the stem to thr heaters. llowever, because the heaters will require $\sim 40 v$ at $2500 \mathrm{~A}$, a second conditioning and conversion to direct current wi.il be accomplished by a converter in the holc-forming assembly near the heated penetrator."

2. Coolant Supply. The coolant is injected at ground level; surface equipment will therefore consist of coolant purms and, if wacer is used, of an additional cooling tower and recycling arrangement. Because the reck-melt debris will be swept out of the hole by the coolant return, a method for debris separation must be provided if the coolant is water.

3. Control Console. The guidance and control system will require a data-conditioning and computing system in a control console at ground level. This computer will process data from the attitude and advance-rate sensors and will send control signals to the heater to control the advance rate, and to the packer-thruster system to steer the Geoprospector along a predetermined course. All readings of diagnostic instrumentation monitoring the meltingface temperatures, thrust forces, heater performance, and power settings are also processed and displayed on the control console.

4. Stem Handling and Core Retrieval. Operations at the surface involve the adding of additional flexible stem sections as required. Some thrust loads, and retraction forces, will probably be applied to the stem at ground level to supplement the thrust loads generated by the packer-thruster system. A quick-disconnect coupling will be provided at the stem terminus for the power, coolant, and control conduits. The core-retrieval system must also be compatible with the stem arrangements at ground level.

A conceptual arrangement of the surface support units is shown in Fig. 10.

\section{DESIGN AND DEVELOPMENT \\ A. Tentative Configuration and System Arrangements}

The functions of the components in the systems defined in pieceding sections are interrelated, as shown in Fig. 2. Their interdependence, which is essential for proper overall operation of the Geoprospector, is clearly indicated. Although the

"An alternate approach would connect the heaters in series which would require only $\sim 210 \mathrm{~A}$ at $\sim 509 \mathrm{~V}$. 


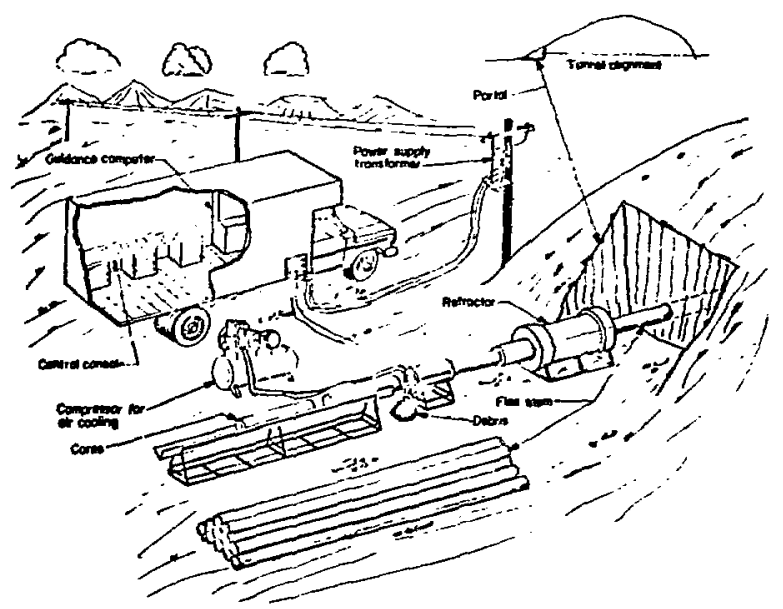

Fig. 10. Surface support units.

relatively strict dimensiongl. and space constraints dictate that design tradeoff and compromises between the various components be carefully coordinated, the physical arrangement of the Geoprospector will essentially follow the idcas outlined in Fig. 1 and Figs. 3 through 10 .

\section{B. System Development Sequencing}

Figure 11 is a flow diagram in network format, which shows the projected sequence development activities and their interconnections, together with the time sequence and constraints among the various development efforts.

\section{Model Design and Construction}

The ideas developed in the conceptual design study will be used to construct a full-scale model of the Geoprospector from inexpensive materials to demonstrate the arrangements of the various system components. The model, which will be assembled and disassembled in a manner similar to the actual Geoprospector, will be useful as a three-dimensional design aid to permit the evaluation of design ideas at an early and relatively inexpensive stage of the final Geoprospector design effort.

\section{Component Design and Analyses}

Because the Geoprospector consists of separate but interrelated systems, the design effort can proceed in logical sequence from component to component. Figure 11 defines the components that will eventually be assembled into the separate systems of the final Geoprospector design. The analysis and the design of each component will be carried out by the cognizant technical activity indicated in the righthand column of Fig. 11 .

E. Laboratory Component Tests

Critical components can be subjected to performance tests in the laboratory under simulated operational conditions at early stages in the design. These tests will aim at detecting deficiencies in component performance so that any deficiency can be corrected as early as possible in the design evolution.

\section{F. Component Integration and Optimization}

As component design progresses and interfacing problems are resolved, component tests of increasing complexity will be conducted to evaluate the performance of interacting components in interrelated systens.

\section{c. Laboratory Tests}

The performance of most penetrators can be evaluated on rock specimens in laboratory test setups. Although the relatively large size of the Geoprospector will cause some difficulties in performing complete evaluation tests under laboratory conditions, the performance of penetrator body and melting face can be observed effectively and compared to theoretical predictions in rock specimens about $3-\mathrm{m}$ in diameter and 6-m long.

Other major systems that can be almost completely checked out in the laboratory are: heaters, power supply, packer-thruster, coolant, orientationsensing and guidance, and rock glass forming-anddebris removal systems. The remaining components (i.e., flexible stem, core sampling-and-retrieval system, and surface equipment) can be partially checked out and evaluated in laboratory tests. H. Final Design Optimization and Analyses

Final design optimization prior to actual field testing will be carried out at the conclusion of laboratory testing. Simultaneously, all analyses will be updated to obtain a current, complete analytical prickage of predicted behavior.

I. Field Tests

The last development steps consist of field tests of the Geoprospector. Initial tests will be limited to short penetration distances of a few hundred metres in soft rock, such as tuff, which has been well characterized in previous Subterrene experiments. Optimum operational procedures will be defined during these tests. Melting performance, glass-forming, 


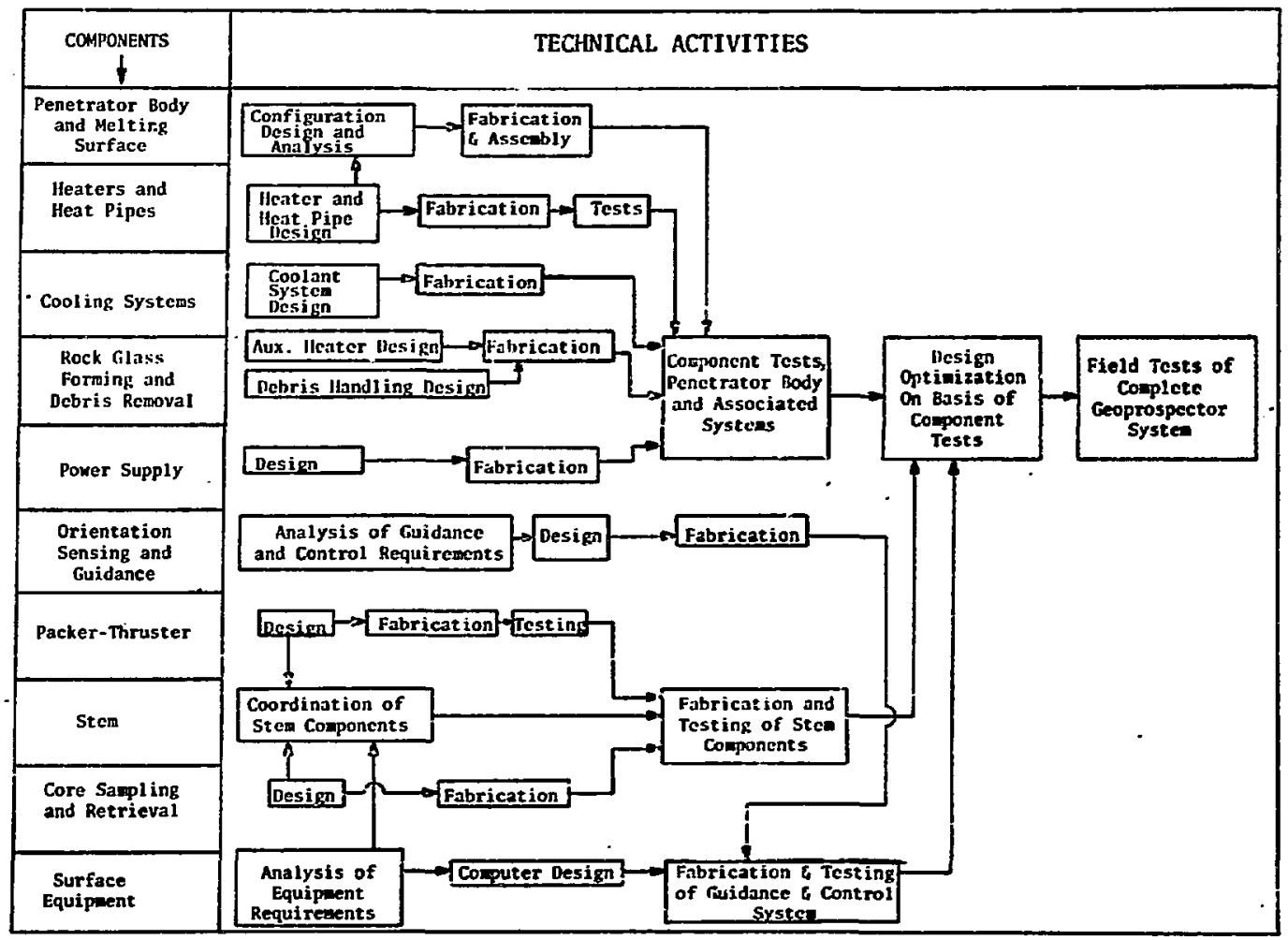

Fig. 11. Geoprospector development sequence.

and core-retrieval techniques will receive particular attention. The accuracy of the guidance and control system will be evaluated under field conditions. Typical problem areas are the development of operational procedures for coupling the power, coolant, and core-retrieval hardware across the flexible stem section joints as they are added at the tunnel entrance.

The operatiun procedures developed during the field tests and the perfoxmance data obtained will form the basis for an operating manual to ensure efficient Geoprospector use.

\section{COST ESTIMATES AND ECONOMIC EVALUATIONS}

A. Initial Fabrication Cost Estimates

Preliminary fabrication cost estinates for the Geoprospector based upon job-lot fabrication of from 10 to 20 units are shown in Table III.

Total cost of a Geoprospector after initial development is thus estimated at $\sim \$ 700,000$ for a one-kilometre system; each kilometre thereafter up to the total design capability of five kilometres would increase cost by $\$ 350,000$. A five-kilometre system thus would cost about 2.1 million dollars in 1973.

\section{B. Field Operation Costs}

The costs of field testing during deiign and development can be based on factors that are currently estimated as follows:

Penetrator melting-surface lifetime 500 hours

Lifetime of all other components 5 years

Operating crew

3 to 5 men

Utilization factor

$75 \%$

These cost factors will be refined as operating experience is gained during development of the fieoprospector.

\section{Cost Effectiveness}

There are two major objectives for the deveiopment of the Geoprospector syster. First, many problems inherent in perfecting a large (10-m-diam) nuclear-powered tunneler of vehicular size can be investigated, defined, and solved in such a 300-mr-diam 


Refrictory metal penetrator and components,
including glass-forming sectior:
Heater assembly
Power supply system
Packer-thruster system
Orientation-sensing and guidance packige
Core sampling and retrieval syster
Flexible stcm, per kilometre
Coolant and debris-removal system
Surface support equipment, including
maintenance facilities

$\begin{array}{r}\text { Cost, } \$ \\ \hline 25,000 \\ 8,000 \\ 12,000 \\ 6,000 \\ 8,000 \\ 6,000 \\ 350,000 \\ 20,000 \\ \text { TOTAL } \\ \hline\end{array}$

unit with great savings in time, expense, and hardware complexity. Second, the Geoprospector will melt a hole of a size useful for many applications, including the retrieval of geological cores along proposed routes of larger tunsels. This urgently needed function has been cited by one industry leader, A. A. Mathews, as follows: 10 "Accurate prediction of geological conditions is one of the most important aspects (author's underline) of any tunnel project. And as the speed of tunneling in predicted conditions increases, the importance of anticipating unusual or anomalous conditions muitiplies. By the same token, obtaining adequate information in advance becomes increasingly difficult."

Deriving specific cost-effectiveness estimates for the projected Geoprospector is extremely difficult and will require a detailed benefit/cost analysis. In view of the fact that expenditures for almost every tunnel of vehicular size amount to at least ten million dollars any appreciable percentage of this sum that can be saved becomes very significant.

\section{SUMMARY AND CONCLUSIONS}

We have presented the preliminary design description of a $300-m m-d i a m$ electrically powered minitunneling machine called a Geoprospector. The conceptual and functional designs of the components of the complete system are discussed and performance specifications outlined. The technical problems inherent in detail design and testing of this rockvielting minitunneler are seen to be either extensions of existing state-of-the-art technology or incorporations of rock-melting techniques currently being investigated. The design, construction, and feasibility demonstration of a Geoprospector will offer a small, relatively inexpensive vehicle for the solution of major problems and features of a large tunneling machine with a diameter of up to four metres.

\section{REFERENCES}

1. E. S. Robinson et al., "A Preliminary Study of the Nuclear Subterrene," Los Alamos Scientific Laboratory Report i 9-4547 (April 1972).

2. R. J. Hanold, "Large Subterrene Rock-Melting Tunnel Excavation Systems," Los Alamos Scientific Laboratory Report LA-5210-MS (February 1973).

3. J. H. Neudecker, "Design Description of MeltingConsolidating Prototype Subterrene Penetrators," Los Alamos Scientific Laboratory Report LA-5212MS (February 1973).

4. J. W. Neudecker, A. J. Giger, and P. E. Armstrong, "Design and Development of Prototype Universal Extruding Subterrene Penetrators," Los Alamos Scientific Laboratory Report LA-5205-MS (March 1973).

5. R. G. Gido, "Description of Field Tests for RockMelting Penetration," Los Alamos Scientific Laboratory Report LA-5213-MS (February 1973).

6. D. L. Sims, "Identification of Potential Applications for Rock-Melting Subterrenes," Los Alamos Scientific Laboratory Report LA-5206-MS (February 1973). 
7. D. L. Sims, "A Versatile Rock Melting System for the Formation of Small Diameter Horizontal Glass Lined Holes," Los Alamos Scientific Laboratory Report LA-5422-MS (October 1973).

8. P. E. Armstrong, "Subterrene Electrical lleater Design and Morphology," Los Mlamos Scientific Laboratory Report LA-5211-PIS (February 197.3).
9. J. E. Kemme, "Heat Pipe Design Considerations," Los Alamos icient ific Laboratory Report LA-4221-1S (August 1969).

10. A. A. Mathews, "The Future and its Complications," rroc. Sccond Symposium on Rapid Fxcavation, Sacramento, $\mathrm{C} A$, December 1969. Section 14, pp 1-12.

\section{APPENDIX}

T. L. Mfilonald

ESTIMLATE OF REQUIREC ORIENTATION PRECISION

It is desired that the Geoprospector guidance system be of sufficient accuracy to allow the system to travel a relatively straight line over a distance of $5 \mathrm{~km}$ and pass through a target with a diameter of $1.0 \mathrm{~m}$.

The two basic modes of control are open-loop and closed-loop. In the open-loop mode one knows, or presumes to know, a priori, the path of travel of the Geoprospector for a given control action. The device is made to follow a designated path by sending out the control signals appropriate for that path. In the closed-loop mode selected parameters such as position, orientation, and acceleration are monitored to determine the trajectory of the holeforming assembly, and appropriate action is taken by an automatic control system to ensure that the trajectory is correct.

The closed-1oop control scheme is more complex than the open-loop scheme; however, the open-loop scheme requires more knowledge of the overall system (or demands less error of control) than the closed-loop scheme. Because the Gecprospector will generally penetrate into unknown soil and rock formations, we assumed at this stage that the effects of control actions are not known with sufficient precision to employ the open-1oop mode of control. We will therefore assume that closed-loop control will be utilized.

Possible elements that could be used to measure penetrator orientation are:

- Magnetic sensor

- Gravity sensor

- Gyroscope.

If the orientation of the unit could be measured precisely in relation to a set of fixed reference axes, then, together with the length of advance, the location of the drill could be determined with precision. This is shown in Fig. A-1. Knowing the angles $\theta_{x}, v_{y}, \theta_{z}$, the displacements in the $x, y$, and $z$ directions for an incremental length of travel, de, are given by:

$$
\begin{aligned}
& \mathrm{dx}=\cos U_{\mathrm{x}} \mathrm{d} \ell \\
& \mathrm{dy}=\cos \theta_{\mathrm{y}} \mathrm{d} \ell \\
& \mathrm{dz}=\cos \theta_{z} \mathrm{~d} \ell
\end{aligned}
$$

Integrating these relations over the length of travel gives the position along the $x, y$, and $z$ axis, respectively.

Consider now the effect of error in measuring the angles. Let

$$
\tilde{\theta}=\theta+\epsilon
$$

$\infty$

where $\theta$ is the angle measured with respect to the $z$ axis, $\theta$ is the actual angle, and $\epsilon$ is tite

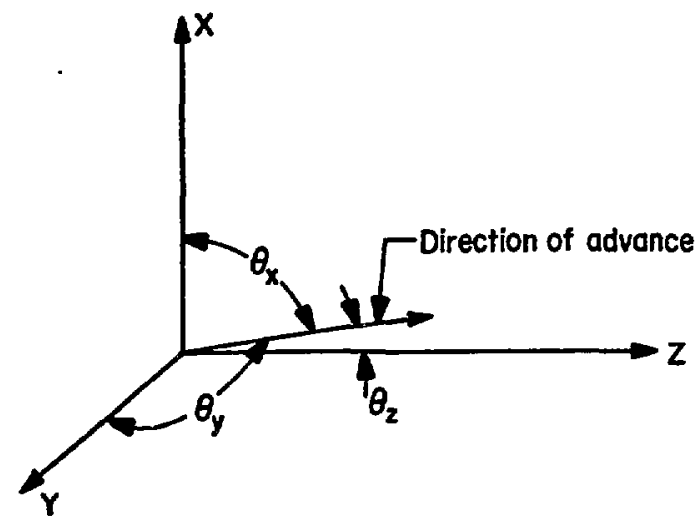

Fig. A-1. I1lustration of orientation measurements. 
measurement error. The distance, $x$, transverse to $z$ axis which is determined from the neasured angle $\widetilde{\theta}$ is given by

$$
x=\int_{0}^{L} \cos (\theta+\epsilon) d \ell
$$

or

$$
x=\int_{0}^{L}(\cos \theta \cos \varepsilon-\sin \theta \sin \varepsilon) d \mathcal{d} \cdot(A-1)
$$

Assuming that the desired direction of travel is in the $z$ direction and $\epsilon$ is small, the following approximate relations hold.

$$
\begin{aligned}
& \theta \approx 90 \mathrm{deg} \\
& \cos \theta \approx 0 \\
& \sin \theta \approx 1 \\
& \cos \epsilon \approx 1 \\
& \sin \epsilon \approx \epsilon .
\end{aligned}
$$

Substituting these approximations into Eq. (A-1), the magnitude of the distance $|x|$ from the $z$ axis to the actual path of travel is given by

$$
|x| \approx\left|\int_{0}^{L} \epsilon d l\right|
$$

Let $\varepsilon_{\mathrm{m}}$ be the maximun value of $e$ so that one can write

$$
|x| \leq \epsilon_{\mathrm{m}} L .
$$

In the situation to be considered $L$ is $5 \mathrm{~km}$ and the unit is required to pass through a target with a diameter of $1 \mathrm{~m}$. Therefore, from $\mathrm{Eq} .(A-2)$,

$$
|x|=1.0 \mathrm{~m}
$$

$$
\epsilon_{m}=1.0 \mathrm{~m} / 5 \mathrm{~km}=0.20 \times 10^{-3} \mathrm{rad} \equiv 0.011 \mathrm{deg}
$$

and thus,

$$
\epsilon \leq 0.011 \mathrm{deg} \text {. }
$$

This result indicates that a relatively precise sensor is required to measure angular deviations.

A more refined error analysis is clearly indicated, which should include the characteristics of specific sensors and a more detailed controlsystem definition. However, this preliminary precision estimate indicates that the proposed system is possible with present sensor capabilities. 